\title{
Smoke Spread in Underground Metro Station
}

\author{
Mahmoud A. Ahmed, Mahmoud A. Fouad, and Essam E. Khalil * \\ Mechanical Power Engineering Department, Faculty of Engineering, Cairo University, Giza, Egypt
}

\begin{abstract}
In the event of subway train fire smoke is the most fatal factor because smoke spreads in direction coincide with passenger's evacuation path. It reduces visibility and can cause fatalities by asphyxiation. This research presents a numerical study to investigate the effect of exhausting smoke by single point extraction and exhausting smoke by multipoint extraction on passengers' life safety. Also, effect of adding smoke barriers at stairs entrance on passengers' life safety is studied. Fire Dynamics Simulator (FDS) software version 5.5.3 is utilized to simulate 6 case studies in $150 \mathrm{~m}$ long, $20 \mathrm{~m}$ wide and $13 \mathrm{~m}$ height domain with a subway car fire source simulated as a fire with unsteady heat release rate of $35 \mathrm{MW}$ resulted from burning Heptane as a fuel. Results show that exhausting smoke by multipoint extraction system in underground subway station gives better performance than single point extraction system. By increasing the distance between vents in multipoint extraction system, tenable conditions improves at human level. Smoke barrier addition to ventilation system has a great effect on the efficiency of smoke extraction and improving tenable conditions at human level.
\end{abstract}

Keywords: Subway train fire, Smoke spread, FDS, Smoke barrier, Life safety.

\section{Introduction}

In recent decades, underground subway transportations have been developing to overcome overpopulation .In case of fire accident in underground subway stations, smoke produced from combustion is considered the most killing factor as it spreads in direction coincide with evacuation path. The term smoke is used to describe liquid and/or solid particulates produced by combustion of fuel materials, suspended in a mixture of air and gaseous products of combustion, including steam. Products of combustion mainly contain toxic gases; carbon monoxide is the most common in building fires. Smoke particles can irritate human eye, consequently the visibility is reduced as the passengers can't open their eyes and see stairs or emergency exits, and also it can be hazardous to passengers who are suffering from asthma. The reduction of visibility is not a direct threat to people life but, it extend evacuation time, thus people can be exposed to toxic gases for more time.
People that exposed to smoke can be suffocated due to oxygen reduction by combustion process. Also, passengers can be exposed to hot gases or heat radiation from smoke layer. The accident of fire in Daegu Subway, South Korea on February 18, 2003 is one of the catastrophic accidents. All six coaches of the train were burned within $2 \mathrm{~min}$ as the interior of the train was made of high flammable material. The damage of lives were 192 deaths and 148 wounded [1]. Such accidents call attention to the importance of life safety engineering to guarantee the tenable conditions in case of fire in underground spaces. The tenable conditions at human level given by NFPA are shown in table 1 [2]. Studies have been conducted to enhance smoke control system in underground subway stations and ensure that evacuation path is free of smoke or toxic gases. Roh et al [3] investigated the effect of platform screen doors (PSD) and ventilation on passenger's life safety in a subway train fire.

The study showed that the passengers in platform with PSD and ventilation have much available time of about $400 \mathrm{~s}$ than in case without PSD and ventilation in modeled subway station.

*Corresponding Author

E-mail: khalile1@asme.org

(C) 2016 International Association for Sharing Knowledge and Sustainability

DOI: $10.5383 /$ ijtee. 12.02 .003 
Table 1: Tenable Conditions at Human Level

\begin{tabular}{|c|c|c|}
\hline \multirow{2}{*}{ Hazard } & \multicolumn{2}{|c|}{ Criterion for stated exposure } \\
\hline & Few seconds & 6 minutes \\
\hline Temperature & $60^{\circ} \mathrm{C}$ & $50^{\circ} \mathrm{C}$ \\
\hline $\mathrm{CO}$ & $2000 \mathrm{ppm}$ & $1500 \mathrm{ppm}$ \\
\hline Air velocity & Up to $11 \mathrm{~m} / \mathrm{s}$ & $\begin{array}{l}\text { Up to } 11 \\
\mathrm{~m} / \mathrm{s}\end{array}$ \\
\hline Visibility & $\begin{array}{l}\text { It is recommer } \\
\text { visibility should } \\
\text { above } 30 \mathrm{~m} \text { for } \\
\text { illuminated } 80 \mathrm{~lx} \\
\text { doors and walls. }\end{array}$ & $\begin{array}{l}\text { that the } \\
\text { maintained } \\
\text { internally } \\
10 \mathrm{~m} \text { for }\end{array}$ \\
\hline
\end{tabular}

The subway turnstiles (ticket gate) dramatically increase the evacuation time and bring passenger's life safety danger in a subway train fire. Yanfeng et al [4] used evacuation modeling to estimate the effect of smoke spread on passengers' life safety in case of interchange subway station fire. It was founded that fire smoke would hinder the egress process, forcing part of loccupants to change their escape routes. Passengers will choose the relative safe exits to escape rather than select the shortest route. Hu et al [5] used FDS to investigate the most effective cooperative operation mode of the tunnel rail track area exhaust system and the platform ventilation system in case of a train on fire in underground subway station. Results of this study showed that only starting the over track exhaust (OTE) system can control the smoke more effectively than starting both the OTE system and the under platform exhaust (UPE) system at the same time. Also, results showed that setting the platform ventilation system as exhaust pattern can provide better control performance than setting it as air supply pattern. CFD simulations were carried out by Meng et al [6] to investigate the optimization of ventilation mode for smoke control of train fires at subway station with full-seal PSD or half-height safety door. For subway stations with full-seal PSD, it is better to activate the lobby air supply system and close the platform air supply system. As for the exhaust system, the platform exhaust system and the over track exhaust are both needed to be activated, and it is better to activate the tunnel ventilation fan. And For subway stations with half-height safety door, the optimization of the ventilation mode is similar to that for subway stations with full-seal PSD. The difference is that even under the same ventilation mode, the environmental conditions of subway stations with half-height safety door is worse than those with full-seal PSD, which indicates that the full-seal PSD helps to restrict the smoke in the tunnel track and to improve the efficiency of the ventilation system. The under platform exhaust is suggested to be deactivated in order to increase the efficiency of the ventilation systems. This study is to investigate the effect of exhausting smoke by single point extraction and exhausting smoke by multi-point extraction on life safety of passengers. The effect of increasing distance between exhaust vents on life safety of passengers is studied. Also, effect of smoke barrier addition to the ventilation system on life safety of passengers is studied.

\section{CFD modeling}

\section{Physical Model}

The station under investigation is a real subway station which is "Albohoos" Cairo Metro Line 2, which has three basements. Basement 1 has staff rooms and ticket office, there are four exits to the ground and it contains ticket gates. Basement 3 has eight stairs to basement 2, each one has dimensions (width $\times$ height $=3.6 \mathrm{~m} \times 5.5 \mathrm{~m}$ ) as shown in figure 1.the dimension of the station basements are illustrated in table 2 . The features of train are as follows:

- Number of carriages: 8 carriages.

- Length: $18.25 \mathrm{~m}$, width: $2.5 \mathrm{~m}$, height: $2.2 \mathrm{~m}$ per carriage.

- Number of doors by carriage: Four doors with $5 \mathrm{~m}$ apart per carriage

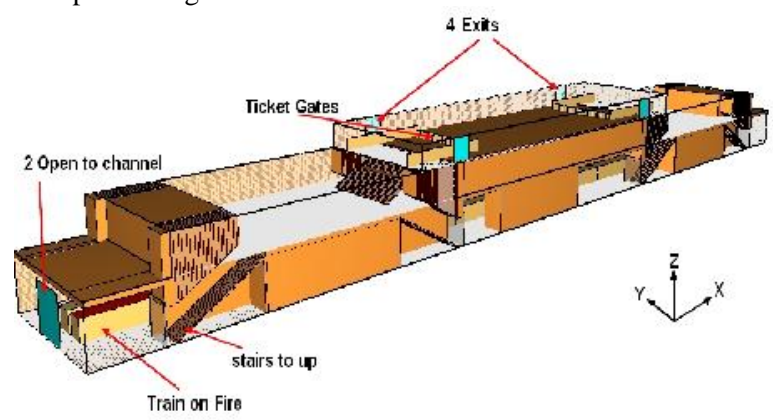

Figure 1: Three Dimensional Model

Table 2: Dimensions of the Station Basements

\begin{tabular}{|c|l|}
\hline Basement & $\mathrm{X}(\mathrm{m}) \times \mathrm{Y}(\mathrm{m}) \times \mathrm{Z}(\mathrm{m})$ \\
\hline 1 & $62 \times 20 \times 3$ \\
\hline 2 & $41 \times 20 \times 4$ \\
\hline 3 & $150 \times 20 \times 5.5$ \\
\hline
\end{tabular}

The computational domain used in this study is divided into 4 meshes as shown in figure 2. The number of grids chosen in each mesh is factored by 2's, 3's and 5's to not unduly slow down FDS solver and to achieve optimum solution [7]. The computational domain volume is made 524,480 cells. Six cases are carried out in this study. Case 1 is the case where the station has fire without ventilation, in case 2 the station is ventilated by single point extraction. Cases from 3 to 5 the station is ventilated by multi-point extraction system with different distances between vents. The ventilation system in case 6 is similar the one in case 5 , but smoke barriers are added at stairs entrance. Table 3 summarizes the six cases. The heat release rate (HRR) of the fire was based on measurements of a burning train carriage by Ingason et al [8]. The Heptane fuel is used to simulate the fire. Simulation time is $600 \mathrm{~s}$ after fire ignition by 2 min. Figure 3 shows the position of the smoke extraction points in different cases, Where, $\mathrm{D}$ is the distance between the furthest two vents, $d$ is the distance between two vents, $L$ is the station length.All exhaust fans operate at the beginning of the simulation with $\mathrm{ACH}=25$. 


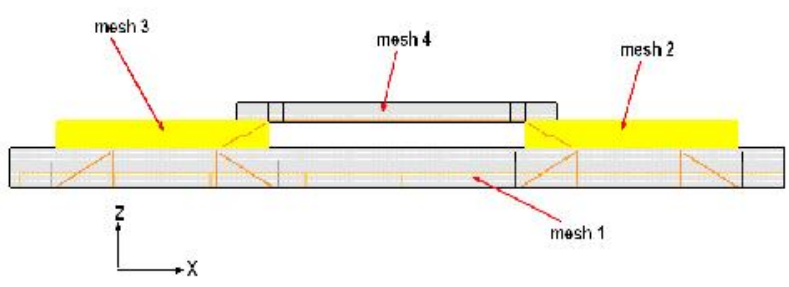

Figure 2 : Computational Domain

Table 3 : Simulation Cases of the Study

\begin{tabular}{|c|c|}
\hline Name & Condition \\
\hline Case 1 & No ventilation \\
\hline Case 2 & Ventilation with single vent, area $=2 \times 2 \mathrm{~m}^{2}$ \\
\hline Case 3 & $\begin{array}{l}\text { Ventilation with four vents, area of each }=1 \times 1 \mathrm{~m}^{2} \text {, } \\
\qquad \frac{D}{L}=5 \% \quad(\mathrm{~d}=2.5 \mathrm{~m})\end{array}$ \\
\hline Case 4 & $\begin{array}{l}\text { Ventilation with four vents, area of each }=1 \times 1 \mathrm{~m}^{2} \text {, } \\
\qquad \frac{\frac{D}{\mathrm{~L}}}{\mathrm{~L}}=20 \% \quad(\mathrm{~d}=10 \mathrm{~m})\end{array}$ \\
\hline Case 5 & $\begin{array}{c}\text { Ventilation with four vents, area of each }=1 \times 1 \mathrm{~m}^{2} \text {, } \\
\qquad \frac{D}{\mathrm{~L}}=80 \% \quad(\mathrm{~d}=40 \mathrm{~m})\end{array}$ \\
\hline Case 6 & $\begin{array}{c}\text { Ventilation with four vents, area of each }=1 \times 1 \mathrm{~m}^{2}, \\
\frac{D}{L}=80 \% \quad(\mathrm{~d}=40 \mathrm{~m}) \\
\text { With smoke barrier at stairs entrance }\end{array}$ \\
\hline
\end{tabular}

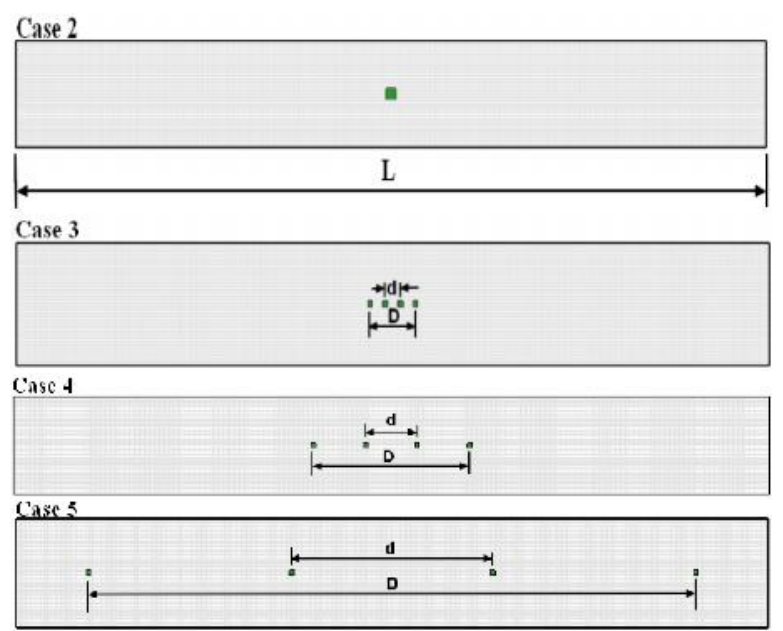

Figure 3: Position of Vents in Different Cases

\section{Governing Equations}

This study uses Fire dynamics simulator (FDS5) to investigate smoke spread in a subway station. FDS [7]was developed by the National Institute of Standards and Technology (NIST), USA. It solves numerically a form of the Navier-Stokes equations appropriate for low-speed, thermally-driven flow with an emphasis on smoke and heat transfer from fires. The core algorithm is an explicit predictor-corrector scheme that is second order accurate in space and time. Turbulence is treated by means of the Smagorinsky model of Large Eddy Simulation (LES). The governing equations of FDS are as following:

Mass conservation can be expressed either in terms of the density, $\rho$,

$\frac{\partial \rho}{\partial t}+\nabla \cdot \rho U=\dot{\mathrm{m}}_{\mathrm{b}}^{\prime \prime \prime}$

or in terms of the individual gaseous species, $\mathrm{Y}_{\alpha}$

$\frac{\partial}{\partial t}\left(\rho Y_{\alpha}\right)+\nabla \cdot \rho Y_{\alpha} U=\nabla \cdot \rho D_{\alpha} \nabla Y_{\alpha}+\dot{m}_{\alpha}^{\prime \prime \prime}+\dot{m}_{b, \alpha}^{\prime \prime \prime}$

The momentum equation in conservative form:

$\frac{\partial}{\partial t}(\rho U)+\nabla \cdot \rho U U+\nabla p=\rho g+f_{b}+\nabla \cdot \tau_{i j}$

The energy conservation equation is written in terms of the sensible enthalpy, $\mathrm{h}_{\mathrm{s}}$

$\frac{\partial}{\partial \mathrm{t}}\left(\rho \mathrm{h}_{\mathrm{s}}\right)+\nabla \cdot \rho \mathrm{h}_{\mathrm{s}} \mathrm{U}=\frac{\mathrm{Dp}}{\mathrm{Dt}}+\dot{\mathrm{q}}^{\prime \prime \prime}-\dot{\mathrm{q}}_{\mathrm{b}}^{\prime \prime \prime}-\nabla \cdot \dot{\mathrm{q}}^{\prime \prime}+\varepsilon(4)$

\section{Validation of FDS}

The experiments done by Hu et al [9] on a long channel is used in validation process of FDS. The experiment with fire size of $0.75 \mathrm{MW}$ is used in testing the validity of FDS to predict smoke behavior in underground fires. The tested parameters in the experiment were maximum ceiling jet temperature, time taken for ceiling jet front to travel, carbon monoxide concentration at an assigned position. Two cases are used for simulation, grid size of $0.2 \mathrm{~m}(\mathrm{x}) \times 0.2 \mathrm{~m}(\mathrm{y}) \times 0.15 \mathrm{~m}(\mathrm{z})$ is used in case 1 . In case 2 , two different grids are used for simulation, grid size of $0.1 \mathrm{~m}(\mathrm{x}) \times 0.1 \mathrm{~m}(\mathrm{y}) \times 0.1 \mathrm{~m}(\mathrm{z})$ is used from $\mathrm{y}=3 \mathrm{~m}$ to $5 \mathrm{~m}$ and grid cells of $0.2 \mathrm{~m}(\mathrm{x}) \times 0.2 \mathrm{~m}(\mathrm{y}) \times 0.2 \mathrm{~m}(\mathrm{z})$ is used in the rest of the domain The simulation results are compared with the experiments and with simulation results done by $\mathrm{Hu}$ et al. It is noted that the simulation can adequately predict the trend of ceiling jet temperature with average absolute error $3.55 \%$ and performs fairly well in modeling the development of $\mathrm{CO}$ concentration with average absolute error $18.7 \%$. The time travel values predicted by FDS very close to that measured in the full scale test with average absolute error $5.5 \%$. 


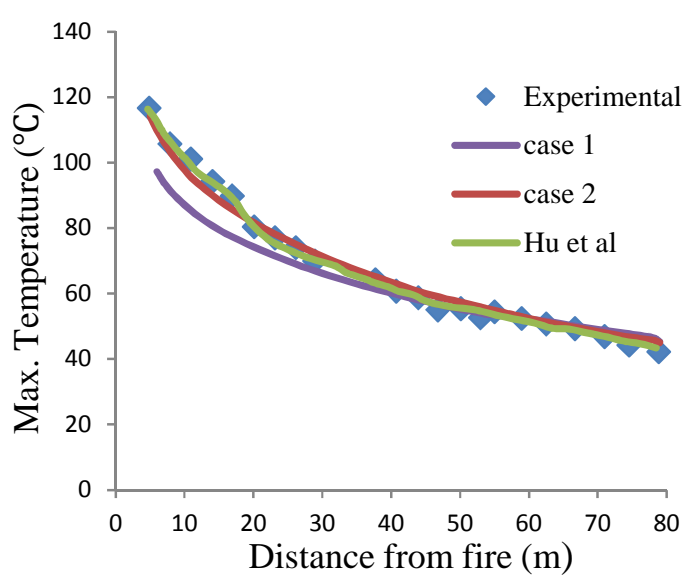

Figure 4 : Comparison of Temperature Variation between Simulation and Experimental Results

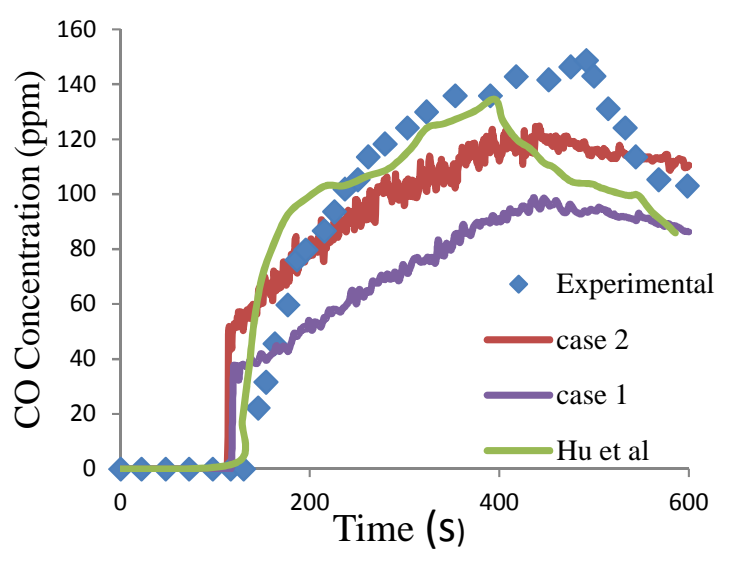

Figure 5 : Comparison of CO Concentration Variation between Simulation and Experiments

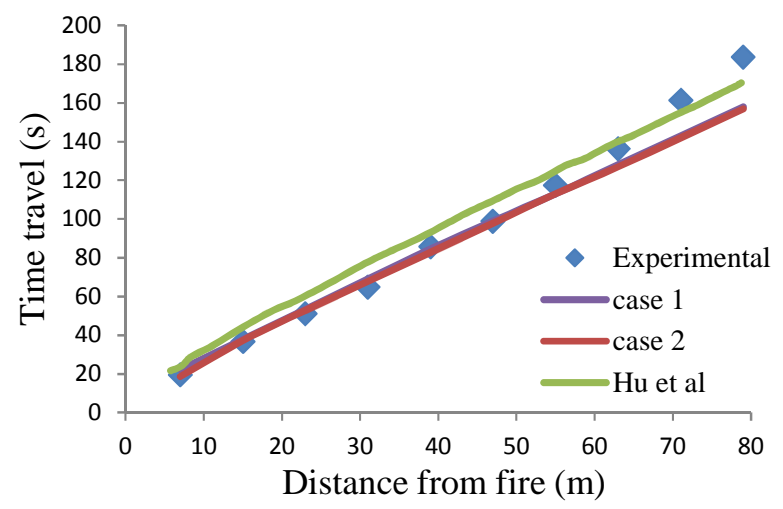

Figure 6 : Comparison of Travel Time of Smoke Flow along the Channel between Simulation and Experimental Results

\section{Results and Discussion}

\section{Visibility}

The visibility contours for cases fire with no ventilation, ventilation with single extraction point and multi points are compared in this section. The tenable condition for evacuees is the visibility should be higher than $10 \mathrm{~m}$ and temperature should not be higher than $60{ }^{\circ} \mathrm{C}$ at human level $(1.8 \mathrm{~m})$ according to NFPA 130 [2] .Figure 7 illustrates the visibility contours at human level in basement 3 at time $300 \mathrm{~s}$. In case 1 the visibility is below the tenable condition nearly $6 \mathrm{~m}$ at all area of the platform except area near the fire, especially near the open tunnel it is higher than $10 \mathrm{~m}$ due to air entrainment.

It can be seen obviously the effect of ventilation on visibility .All cases with ventilation are better than one without ventilation. Although the visibility in cases 2 and 3 improved, there is some part of area in the left half of the station has visibility below $10 \mathrm{~m}$. By increasing the distance between vents, the visibility improves in case 4 and 5 . The effect of smoke barrier on visibility is obvious in case 6.The visibility contours at human level in basement 1 are shown in figure 8 The visibility is poor in case 1 and gets better by increasing the distance between vents to obtain good visibility in case 5 and free of smoke in case 6 . It is concluded that multipoint ventilation with ratio $\mathrm{D} / \mathrm{L}=80 \%$ with addition of smoke barriers at stairs entrances is the best case for the visibility at human level.

\section{Temperature Distribution}

The temperature contours at human level in basement 3 at 300 $\mathrm{s}$ are presented in figure 9 . The temperature in case 1 is higher than $60{ }^{\circ} \mathrm{C}$ in almost the platform area and decreased below 50 ${ }^{\circ} \mathrm{C}$ in case 2 and 3 , except the area near the fire is still higher than $60^{\circ} \mathrm{C}$ and it decreases by increasing the distance between vents in case 5. Also smoke barriers have a good effect on temperature distribution at human level. Figure 10 shows the temperature contours at human level in basement 1 . The results show that temperature at human level in all cases is below the critical. The average temperature in case 1 is the highest and decreases to reach the lowest in case 6.

\section{Carbon Monoxide Concentration}

Figure 11 shows $\mathrm{CO}$ concentration in ppm in basement 3 at human level at time 300 s.It is noticed that all cases are below the critical value of $\mathrm{CO}$ concentration which is $1500 \mathrm{ppm}$ according to NFPA 130. As shown in case $1 \mathrm{CO}$ concentration in the right half of the platform is higher than the left half. In case $2 \mathrm{CO}$ concentration in all area reduced to $15 \mathrm{ppm}$ due to ventilation effect except the area near the fire it is above 25 $\mathrm{ppm}$. There is slight reduction in CO concentration in case 3 . The reduction of $\mathrm{CO}$ concentration is observed by increasing the distance between vents in case 4 and case 5. Case 6 shows good effect of smoke barrier on $\mathrm{CO}$ concentration at human level. Figure 12 illustrates $\mathrm{CO}$ concentration in basement 1 at human level at time $300 \mathrm{~s}$. In case 1 the concentration in area near stairs is higher than area in the middle in general $\mathrm{CO}$ concentration is higher than $35 \mathrm{ppm}$. In case 2 the concetration decreased to below $30 \mathrm{ppm}$ and reduction continues in case 3 and 4 by increasing distance between vents to get less concentration in case 5. Smoke barrier effect is very clear in case 6 that there is zero $\mathrm{CO}$ concentration at human level It is concluded that increasing distance between vents leads to reduction in $\mathrm{CO}$ concentration, also smoke barriers have a great effect on decreasing $\mathrm{CO}$ concentration especially in basement 1. 


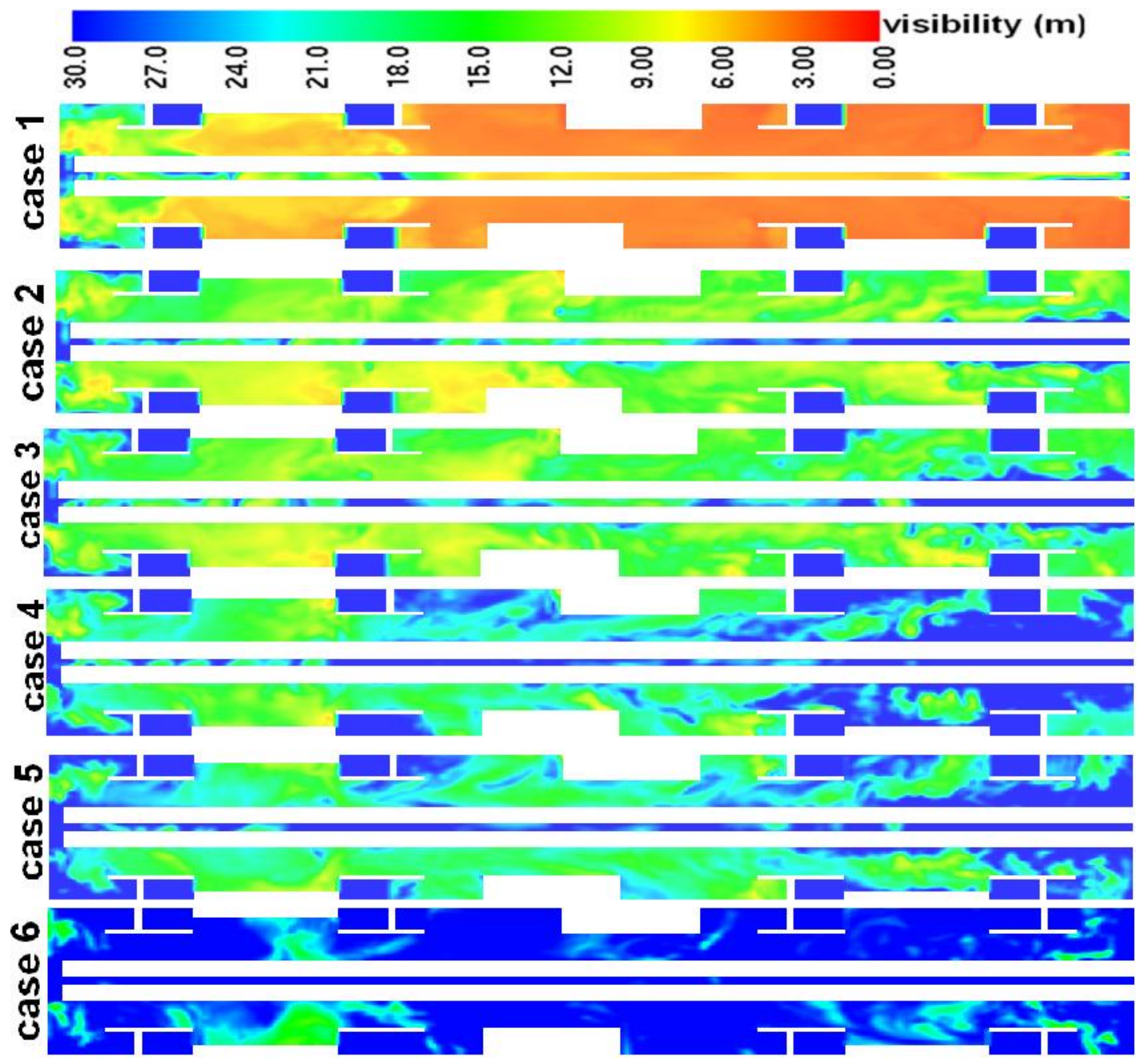

Figure 7: Visibility Contours at $Z=1.8 \mathrm{~m}$ (Basement 3) at Tme $300 \mathrm{~s}$ for Cases 1, 2,3,4,5 and 6
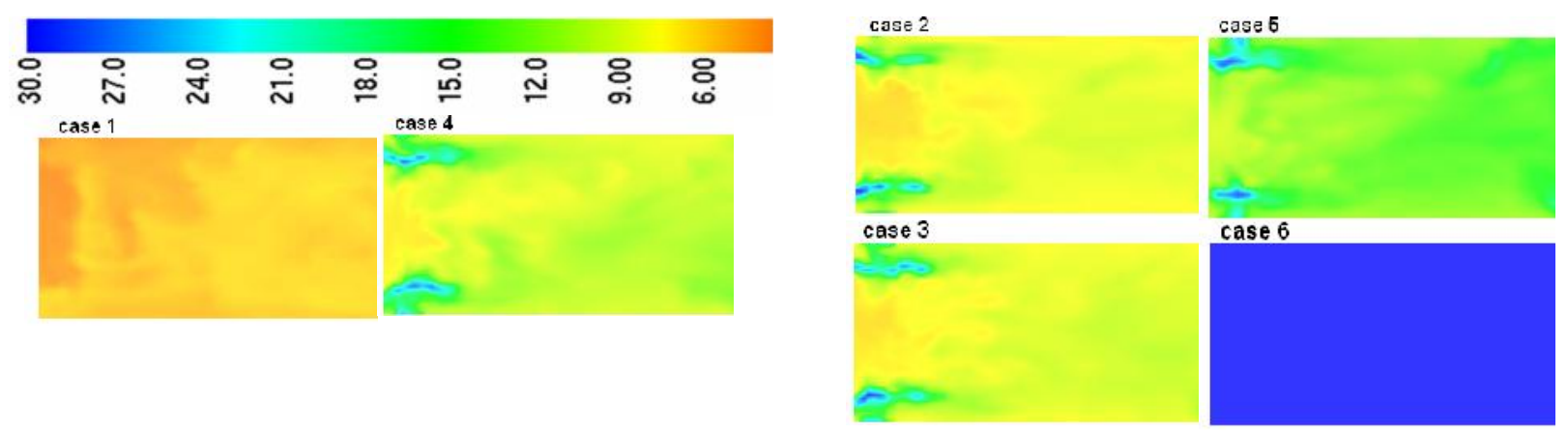

Figure 8: Visibility Contours at $Z=11.8 \mathrm{~m}$ (Basement 1) at Time $300 \mathrm{~s}$, for Cases 1 to 6 


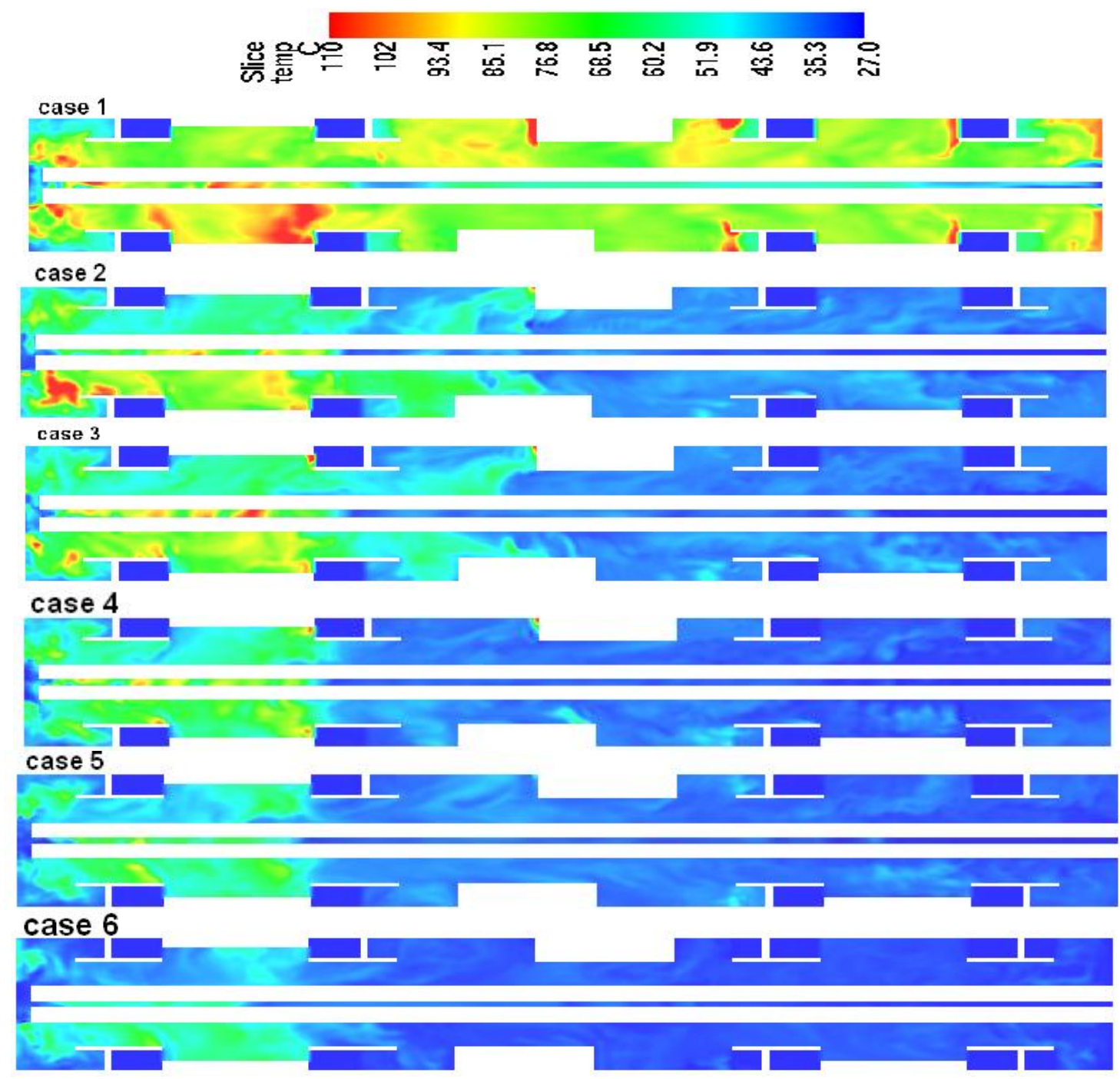

Figure 9 : Temperature Contours at $\mathrm{Z}=1.8 \mathrm{~m}$ (Basement 3) at time $300 \mathrm{~s}$, for Cases 1,2,3,4, 5 and 6

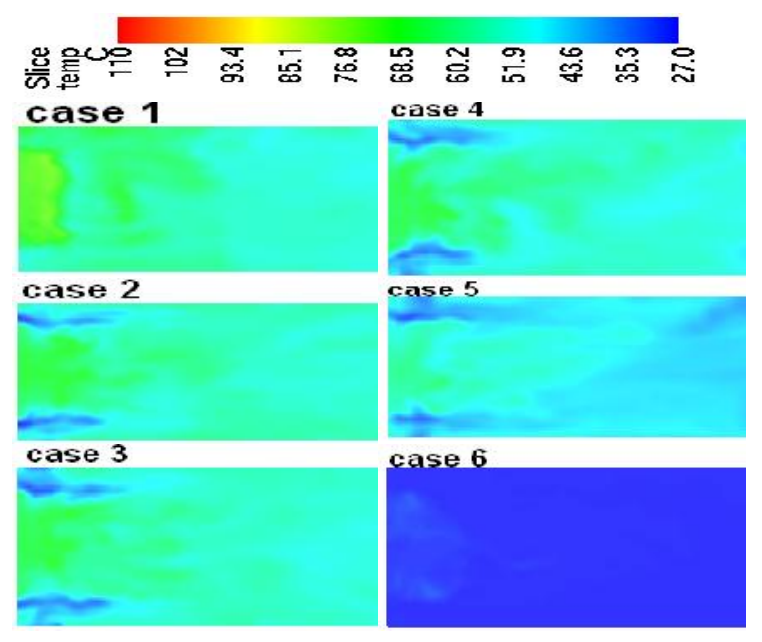

Figure 10 : Temperature Contours at $\mathrm{Z}=11.8 \mathrm{~m}$ (Basement 1) at time $300 \mathrm{~s}$, for Cases 1,2,3,4, 5 and 6

\section{Velocity Distribution}

Figure 13 shows the velocity distribution at human level in basement 3 for cases from 1 to 6 . In all cases, fire entrains air from two open of tunnels and maximum velocity for air is in the middle of platform because of minimum cross section area. In case 1 average velocity at centre of platform reaches $1.5 \mathrm{~m} / \mathrm{s}$. In case 2 , velocity increases to $2.5 \mathrm{~m} / \mathrm{s}$ as a result of ventilation. Also air is drawn from stairs of the right side of station. Case 3 has no significant change in velocity distribution and case 4 has a little improvement. Increasing the distance between vents, improves velocity distribution as seen in case 5. Case 6 shows the great effect of adding smoke barriers at stairs entrances where velocity improved very well, it can be said that velocity distribution is better than one in natural case. It can be concluded that increasing distance between vents in smoke exhausting systm makes velocity distribution better which improves very well by adding smoke barriers. Maximum velocity in all cases is below the criteria of NFPA130 [2] 


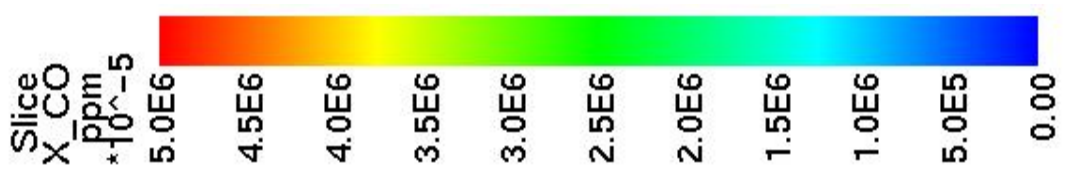

Case 1
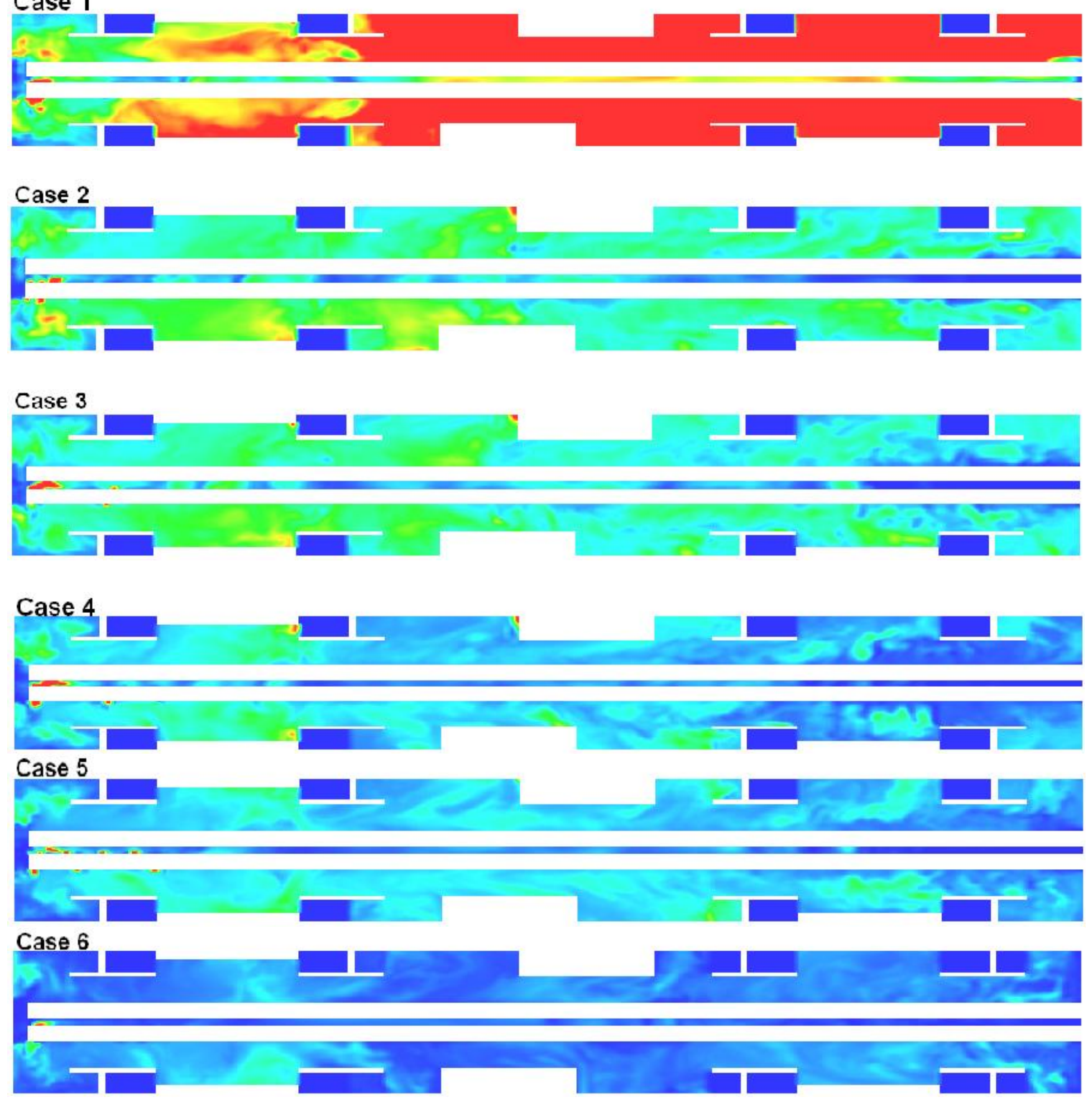

Figure 10: CO Concentration at $Z=1.8 \mathrm{~m}$ (Basement 3) at Time $300 \mathrm{~s}$, for Cases 1,2,3,4, 5 and 6 

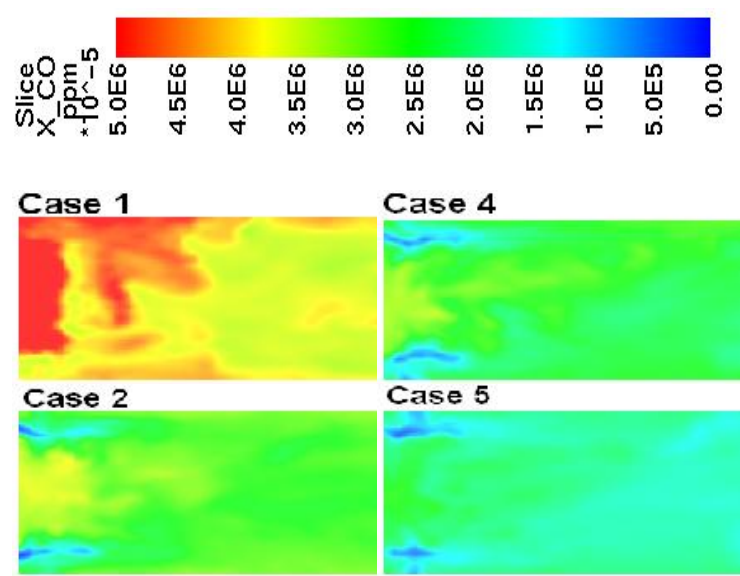

Case 3

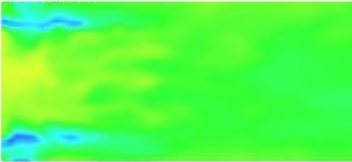

Figure 11 : CO Concentration at $\mathrm{Z}=\mathbf{1 1 . 8} \mathrm{m}$ (Basement 1) at Time $300 \mathrm{~s}$ for Cases 1 to 6

\section{Case 4}

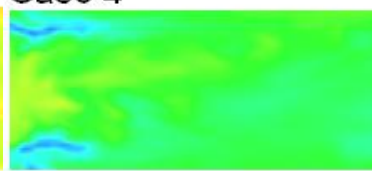

Case 5

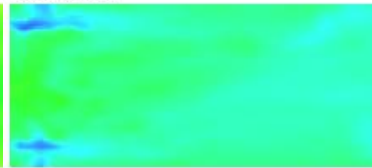

Case 6

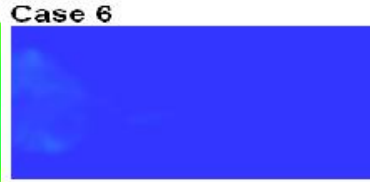

\section{Conclusions}

In this paper, Numerical study is performed to investigate the effect of exhausting smoke by single point extraction and exhausting smoke by multi-point extraction on life safety of passengers. The effect of increasing distance between exhaust vents on life safety of passengers is studied. Also, effect of smoke barrier addition to the ventilation system on life safety of passengers is studied. Major findings and conclusions are:

1. Exhausting smoke by multipoint extraction system in underground subway station gives better performance than single point extraction system.

2. By increasing the distance between vents in multipoint extraction system tenable conditions improves at human level.

3. Smoke barrier addition to ventilation system has a great effect on the efficiency of smoke extraction and improving tenable conditions at human level.

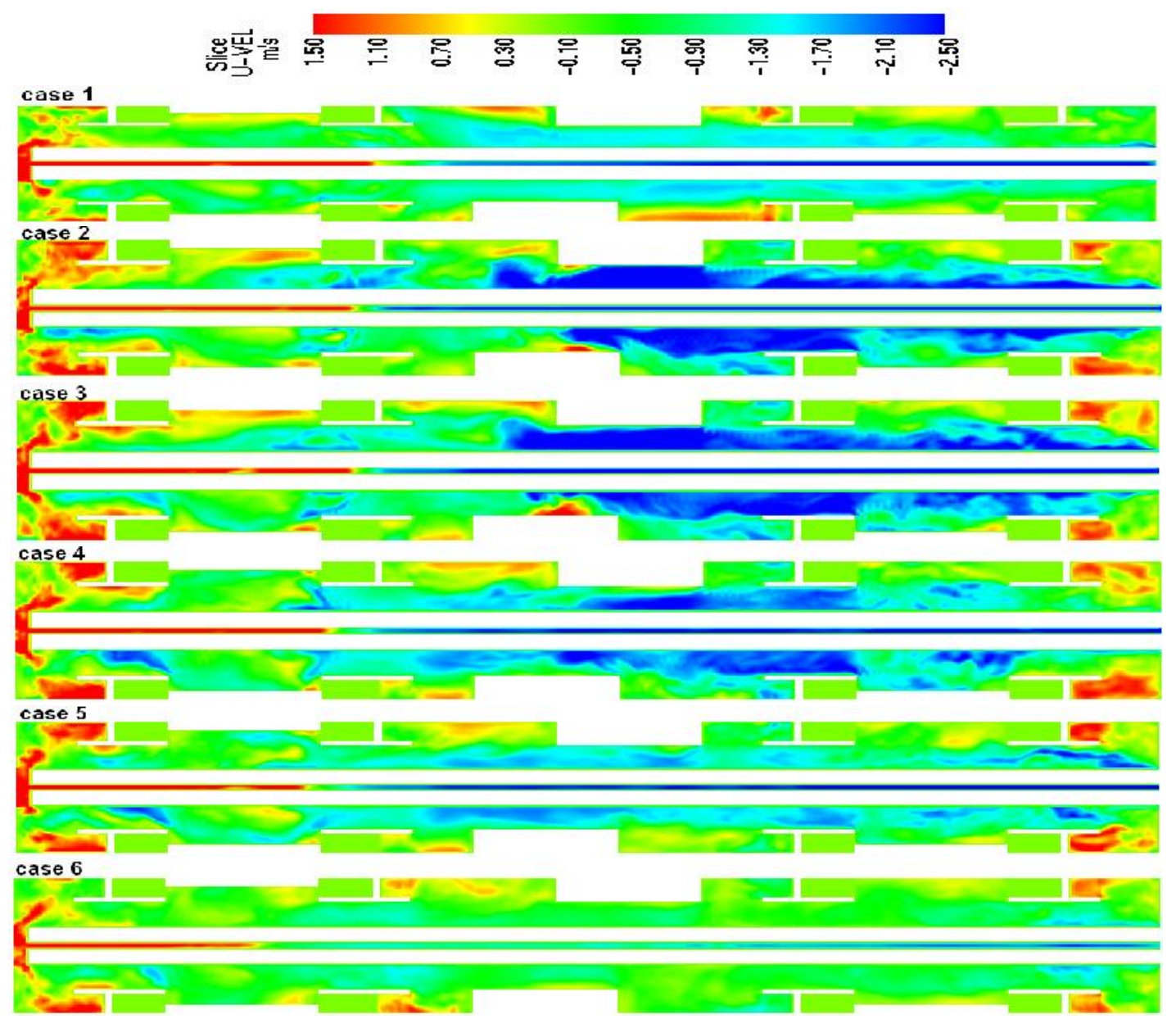

Figure 12: Velocity Contours at $Z=1.8 \mathrm{~m}$ (Basement 3) at Time $300 \mathrm{~s}$ for Cases 1, 2,3,4,5 and 6 


\section{References}

[1] National Emergency Management Agency, Fire in Daegu subway, Disaster Reports - Online, South Korea, 2004.

[2] National Fire Protection Association. NFPA 130,"Standard for Fixed Guide way Transit System", 2003.

[3] Jae Seong Roh, Hong Sun Ryou, Won Hee Park, Yong Jun Jang "CFD simulation and assessment of life safety in a subway train fire", Tunnelling and Underground Space Technology 24 (2009) 447-453.

[4] Yanfeng, L., Xinxin, L., Xiao, F., Chao, W. and Junmei, L.,' Life safety evacuation for cross interchange subway station fire" ,Procedia Engineering, Vol.45, 2012, pp. 741-747.

[5] Hu, L., Wu, L., Lu, K., Zhang, X., Liu, S. and Qiu, Z., "Optimization of emergency ventilation mode for a train on fire stopping beside platform of a metro station" Building Simulation, Vol. 7 ,2013, pp. 137-146.

[6] Meng, N., Hu, L., Wu, L., Yang, L., Zhu, L., Chen, L. and Tang, W.," Numerical study on the optimization of smoke ventilation mode at the conjunction area between tunnel track and platform in emergency of a train fire at subway station".,
Tunnelling and Underground Space Technology, Vol.40,2014, pp. 151-159.

[7] McGrattan, K., Hostikka, S., Floyd, J., Baum, H., Rehm, H., Mell, W., and McDermott, R., "Fire Dynamics Simulator (Version 5) Technical Reference Guide", NIST Special Publication 1018-5. Gaithersburg, MD: National Institute of Standards and Technology, 2010.

[8] H. Ingason, "Heat release rate measurement in tunnel fires. In: Proceedings of the International Conference on Fires in Tunnels," Boras, Sweden, 1994, pp. 86-103.

[9] Hu, L. H., Fong, N. K., Yang L. Z., Chow, W. K., Li, Y. Z. and Huo, R., "Modeling fire-induced smoke spread and carbon monoxide transportation in a long channel: Fire Dynamics Simulator comparisons with measured data," Journal of Hazardous Materials, Vol.140 ,2007, pp.293-298.

[10] Ahmed, M. A Numerical Investigation For Smoke Spread In An Underground Subway Station MSc Thesis, Cairo University, 2014 